\title{
Satellite data for dam safety monitoring
}

Craig Goff BEng, MSC, CEng, FICE, CMgr, MCMI

Technical Director - Dams \& Reservoirs, HR Wallingford Ltd, Wallingford, Oxfordshire, UK (Orcid:0000-0002-6444-9662)

(corresponding author: c.goff@hrwallingford.com)

Eleanor Ainscoe MA, MSc, DPhil

Earth Observation Scientist, HR Wallingford Ltd, Wallingford, Oxfordshire, UK (Orcid:0000-0001-8190-1676)
Ye Liu BA, MA, MPhil, PhD

Principal Data Scientist, HR Wallingford Ltd, Wallingford, Oxfordshire, UK Marta Roca PhD

Principal Engineer, HR Wallingford Ltd, Wallingford, Oxfordshire, UK

The use of datasets from satellites to aid the monitoring of dams has been possible for many years. Within the last five years there has been a rapid development in the type and accuracy of the data available, led by an influx of new satellites and improved access to these datasets. This paper gives an overview of the different types of satellite datasets and satellite infrastructure relevant to dam safety that are currently available, explains the complex processes of converting raw satellite data into useable information and summarises the advantages and disadvantages of each data type along with indications of the level of accuracy and cost. The information presented by the authors is based on experience gained undertaking a 3 year, $\mathbf{f 4} \mathrm{m}$, UK-government-funded research project to investigate and combine many types of space data to improve the monitoring of dams.

\section{Notation}

NIR surface reflectance in the near-infrared band

RED surface reflectance in the visible red band

SWIR surface reflectance in the short-wave infrared

GREEN surface reflectance in the visible green region

\section{Introduction}

Dams have been constructed and used by humanity for over 5000 years to divert or store water for the benefit of societies (Goff et al., 2020). The structure of a dam may take many different forms, from a simple concrete wall to a complex zoned earth embankment with an internal core, but whatever the composition of the dam, it is likely to have to withstand the relentless forces of nature for many decades or even centuries. While a dam failure - defined as an uncontrolled release of water from a reservoir - is typically a very rare event, the consequences of such an event can be catastrophic, leading to significant loss of life. Indeed, deliberate breaching of dams has been used throughout history as a tactic of war (Goff et al., 2020).

Ignoring deliberate malicious acts, there are two main failure mechanisms of large dams: internal erosion and external erosion, accounting for 46 and $48 \%$ of embankment dam failures, respectively (ICOLD, 2017). The dam safety industry globally includes a significant focus on surveillance of dams, in order to spot indicators of either type of failure mechanism developing early enough to take corrective action and prevent failure occurring.

Surveillance has traditionally included periodic visual inspection by specialist dam safety engineers, combined with longterm monitoring of physical properties of the dam such as pore-water pressure within the dam body and settlement of the dam crest. These properties help engineers develop an understanding of the normal behaviour of the structure and thus identify any anomalies. The monitoring 'tools' available to a dam safety engineer are myriad. In situ sensors, such as piezometers, and manual surface displacement surveys can be highly accurate monitoring tools, and are well understood (BRE, 1999). However, there are cases where the remoteness of the site or the frequency of data required make periodic monitoring expensive and thus the opportunity to use satellites for continuous monitoring is attractive.

The use of datasets from satellites to aid the monitoring of dams has been possible for many years. Within the last five years there has been a rapid development in the types and accuracy of the data available, led by an influx of new satellites and improved access to these datasets. This paper gives an overview of the different types of satellite datasets and satellite infrastructure relevant to dam safety currently available; explains the complex processes of converting raw satellite data into useable information; and summarises the advantages and disadvantages of each type along with indications of the level of accuracy and cost.

The information presented by the authors is based on experience gained undertaking the DAMSAT (DAm Monitoring by SATellite) Project, a 3 year, $£ 4 \mathrm{~m}$, UK-government-funded research project to independently investigate and combine many types of space data to improve the monitoring of dams. DAMSAT reviewed and tested datasets from various commercial suppliers, and built a web-based portal capable of accepting multiple satellite data sources. Critically, the DAMSAT team worked with dam safety engineers to develop the complex processing algorithms that make the data meaningful for dam safety applications. 


\section{Datasets relevant to dam safety}

The critical indicators for dam safety are those that could suggest an internal erosion process is starting to develop, or those that could suggest the risk of reservoir water overflowing the dam (thus increasing the chance of external erosion) is increasing. Additionally, periodic examination of maps of the area downstream of the dam help planners quantify the consequences of failure and thus the standards of safety to which the dam must be operated. Table 1 shows the broad failure modes considered; the traditional datasets used for monitoring; and the possible satellite datasets that could also be considered.

The satellite datasets noted in Table 1 can be obtained from many sources, both commercial and open access. They are not always the best solution for monitoring a particular property of a particular dam, as factors such as the aspect of the dam, satellite coverage and track, refresh time, processing rigour, accuracy and cost are all important considerations. As with any other type of monitoring, satellite datasets have their advantages and disadvantages, but they are now sufficiently developed and widely available and so should routinely be considered by dam safety engineers when specifying a monitoring regime for a dam.

\section{Satellite dataset features}

This section describes each of the satellite dataset types in more detail, along with brief discussion of sources, accuracy, frequency and pros/cons of each data type. There are two main types of dataset available - optical and radar. A summary of the different satellite datasets key considerations for dam safety monitoring is shown in Table 2.

\subsection{Optical data - imagery}

Optical imagery is the type of satellite data that readers are likely to be familiar with from Google Earth. It is obtained from satellites that passively measure the solar radiation that comes off the Earth. The satellites' sensors measure various sections or 'bands' of the radiation's spectrum. Because they measure multiple different spectral bands these sensors and datasets are referred to as 'multispectral'.

For natural-looking true colour images for visual inspection the red-green-blue (RGB) bands shown in the area labelled 'VIS' in Figure 1 are used. RGB optical data provide synoptic, accurate and fresh context mapping of an entire site. It can be used for visual comparison of a current image with previous ones in order to detect changes in the areas of interest around the dam and the reservoir. For example, identifying changes of reservoir water surface, vegetation, populated areas or infrastructure. The spatial resolution of images is given by the pixel size and its temporal resolution by how often images are available at a particular location. There are a number of openaccess optical satellite products that can be used, with perhaps the most well-known being Google Earth. This, of course, is currently only updated every few years, so is not as useful as regular open-access satellite data products. In the UK, the

Table 1. Traditional and satellite datasets relevant to dam monitoring

\begin{tabular}{|c|c|c|}
\hline Dam safety aspect (leading to failure mode) & Traditional monitoring datasets & Satellite monitoring datasets \\
\hline Reservoir rim stability (external erosion) & $\begin{array}{l}\text { Visual inspection } \\
\text { Aerial LiDAR survey }\end{array}$ & Interferometric synthetic aperture radar (InSAR) data \\
\hline Reservoir water level (external erosion) & $\begin{array}{l}\text { Manual observation } \\
\text { Pressure transducer }\end{array}$ & Normalised difference water index (NDWI) \\
\hline Overflowing risk (external erosion) & $\begin{array}{l}\text { Statistical hydrology and spillway } \\
\text { design } \\
\text { Visual inspection that spillways } \\
\text { unobstructed }\end{array}$ & $\begin{array}{l}\text { Long-range meteorological forecast data } \\
\text { Optical data showing spillways unobstructed }\end{array}$ \\
\hline Crest settlement (internal or external erosion) & $\begin{array}{l}\text { Manual level survey } \\
\text { Drone photogrammetry } \\
\text { Terrestrial LiDAR scan }\end{array}$ & $\begin{array}{l}\text { InSAR data } \\
\text { Global navigation satellite systems (GNSS) data }\end{array}$ \\
\hline $\begin{array}{l}\text { Leakage/seepage/pollution }{ }^{\text {a }} \text { from reservoir } \\
\text { (internal erosion) }\end{array}$ & $\begin{array}{l}\text { Toe drain flows (manual) } \\
\text { Toe drain flows (sensors) } \\
\text { Piezometers } \\
\text { Visual inspection }\end{array}$ & $\begin{array}{l}\text { Drain flow or piezometer sensors by way of satellite } \\
\text { communications } \\
\text { Normalised difference vegetation index (NDVI) data } \\
\text { Iron oxide trace data }\end{array}$ \\
\hline Structural movement (internal erosion) & $\begin{array}{l}\text { Crack gauges } \\
\text { Inclinometers } \\
\text { Manual survey }\end{array}$ & $\begin{array}{l}\text { InSAR data } \\
\text { GNSS data }\end{array}$ \\
\hline $\begin{array}{l}\text { Leakage from pipelines or reservoir (internal } \\
\text { erosion) }\end{array}$ & $\begin{array}{l}\text { Drain flows } \\
\text { CCTV surveys }\end{array}$ & Soil moisture data \\
\hline Failure consequences (risk level) & Maps of official habitation areas & Optical data showing habitation areas \\
\hline
\end{tabular}

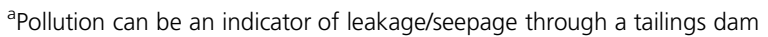




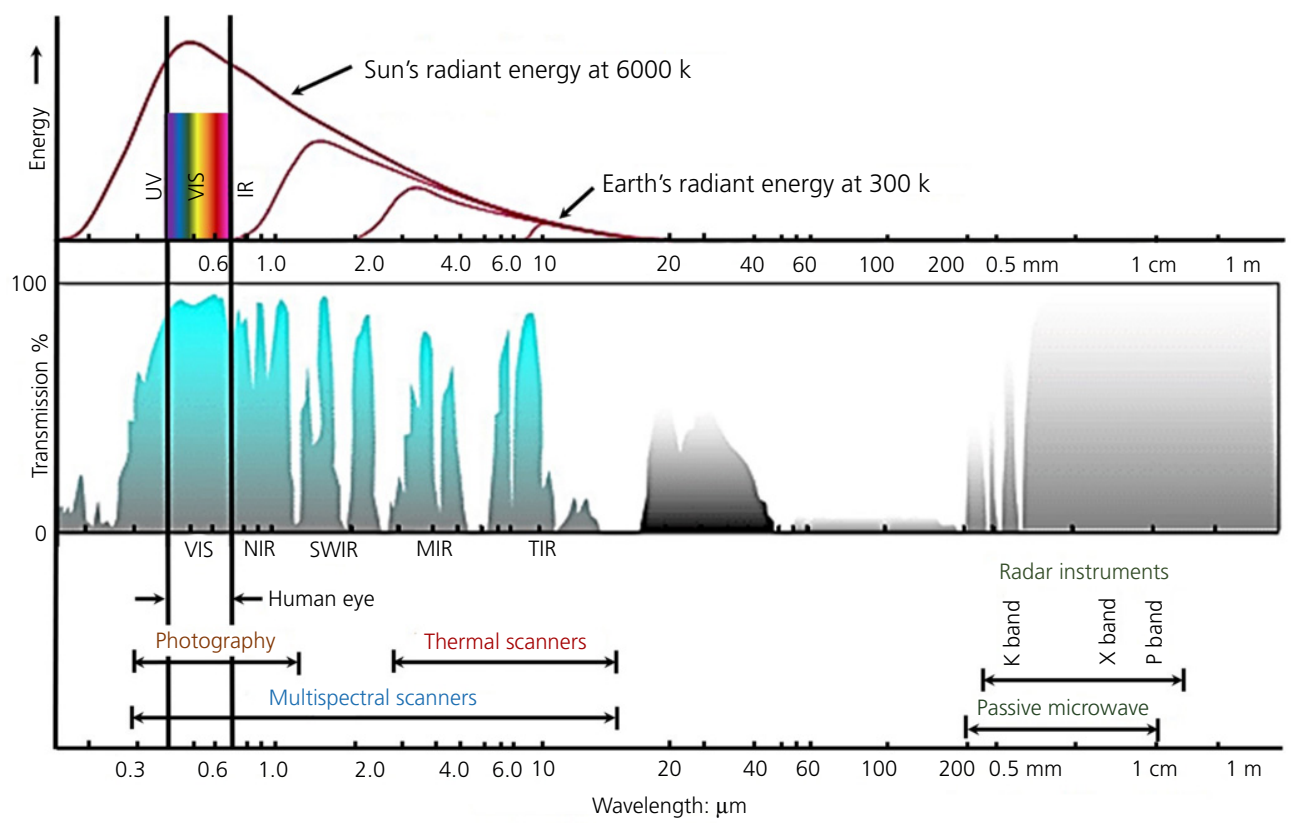

Figure 1. Spectral characteristics of common remote sensing systems (adapted from Lillesand et al. (2015)). Note: transmission chart shows which wavelengths can pass through the Earth's atmosphere. A full-colour version of this figure can be found on the ICE Virtual Library (www.icevirtuallibrary.com)

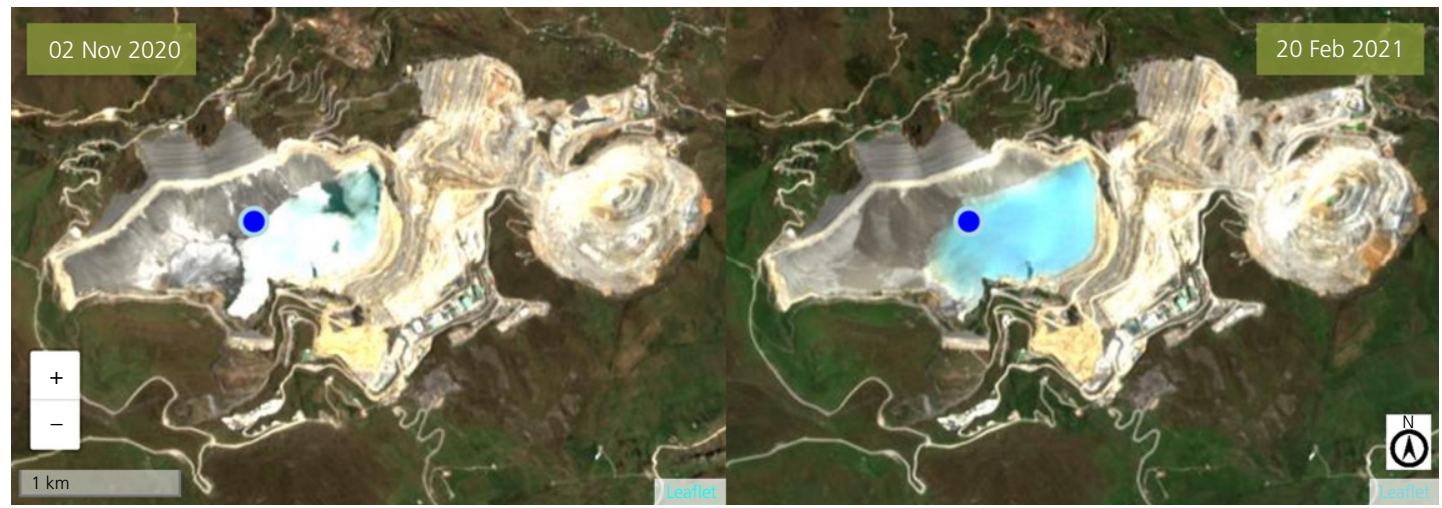

Figure 2. Typical satellite imagery data comparison tool of a dam site in Peru monitored by a regulator (Courtesy of DAMSAT)

European Space Agency Sentinel-2 satellites are the most widely used open-access data for monitoring.

For example, Figure 2 shows the comparison of Sentinel-2 RGB images with $10 \mathrm{~m}$ spatial resolution, which are updated at least every 5 days.

Optical satellite imagery has limitations. Clouds may obstruct the site from view during the period that the satellite is overhead, and the temporal resolution may not prove enough to identify certain changes such as small releases of material that are quickly repaired. In the case of open-access data, the spatial resolution can sometimes be too low to identify certain dam features.

Generally, commercially available imagery data have a higher resolution, with a pixel size as small as $0.31 \mathrm{~m}$ for the highest resolution option, WorldView-3. Very high-resolution satellites typically have red, green and blue bands and one infrared band, meaning that they are useful for making true colour images and for vegetation and water mapping, but cannot be 
used for more sophisticated multispectral analyses, which require more bands.

\subsection{Optical - normalised difference vegetation index (NDVI)}

Multispectral optical data can be used for monitoring vegetation using the normalised difference vegetation index (NDVI). NDVI is a metric for measuring the abundancy of live green vegetation at the sampled location. It is calculated by

$$
\mathrm{NDVI}=\frac{\mathrm{NIR}-\mathrm{RED}}{\mathrm{NIR}+\mathrm{RED}}
$$

where NIR and RED are respectively the surface reflectance in the near-infrared and visible red band. The NDVI is a unitless parameter ranging from -1.0 to 1.0 where higher value implies a greater presence of live green plants.

In general, live green plants re-emit solar radiation in the NIR spectral region (about 750-2500 $\mathrm{nm}$ in wavelength) and absorb solar radiation in the photosynthetically active ratio (PAR) spectral region (400-700 $\mathrm{nm}$ in wavelength, including the RED light at around $700 \mathrm{~nm}$ ). The formulation of NDVI identifies the contrast in the reflectance in those two bands and at the same time provides some nice mathematical properties in the resulting value - for example, defined over a closed interval and comparable across different locations.

In an application for dam safety monitoring, abnormal changes in the NDVI would indicate irregular growth (or decline) of vegetation, which can be related to leakages of water (or tailings
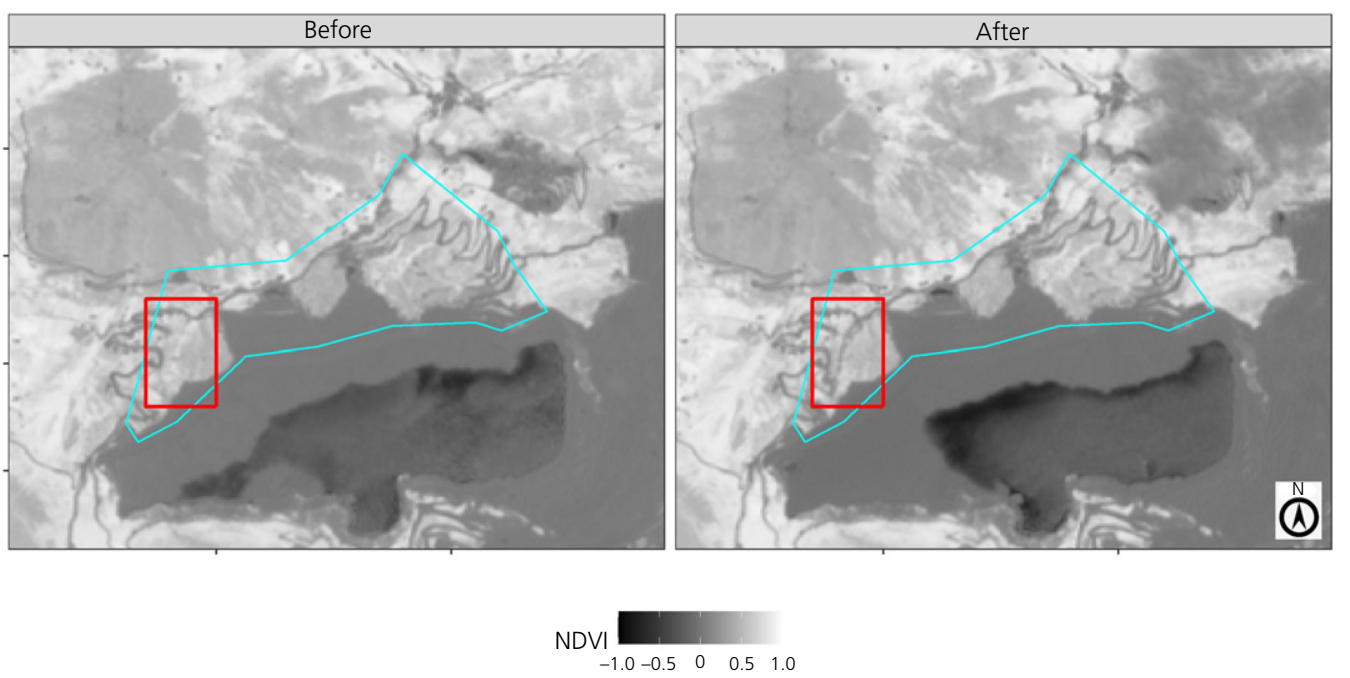

Figure 3. An example showing the change in the NDVI due to dam leakage. (Left) the before NDVI image, where the brighter colour indicates higher NDVI and darker indicates lower NDVI, and (right) the after NDVI image. NB: Polygon denotes area monitored, box denotes location of change detected in the case of a tailings dam). Depending on the type of vegetation, the NDVI usually varies periodically with the season. At other times, the NDVI over a large area could vary outside its normal range due to weather-related reasons - for example, drought or flood. So it is important to account for these factors when designing an algorithm to detect abnormal NDVI values. In general, a sharp increase in the NDVI over a localised area near the dam is more likely related to leakage. Figure 3 shows an example where a known leakage of tailings is visible based on the NDVI images before and after the incident.

One unique feature of an NDVI-based leakage detection method is that when the path of leakage is not exposed or too small to detect directly using remote sensing, the cumulative effect of the leakage will be more prominent and better reflected through the health of the local vegetation. This has the potential advantage of giving early warning of a leakage situation developing.

\subsection{Optical - normalised difference water index}

Similar to the NDVI, the normalised difference water index (NDWI) is an unitless index derived from the multispectral optical data. Unfortunately, two different indices were given the name NDWI:

$$
\mathrm{NDWI}_{1}=\frac{\mathrm{NIR}-\mathrm{SWIR}}{\mathrm{NIR}+\mathrm{SWIR}}
$$

$$
\mathrm{NDWI}_{2}=\frac{\text { GREEN }-\mathrm{NIR}}{\text { GREEN }+\mathrm{NIR}}
$$


where NIR, SWIR and GREEN are, respectively, the surface reflectance in the near-infrared, short-wave infrared and the visible green region. Both indices vary between -1.0 and +1.0 and have similar mathematical properties as the NDVI.

The first variation of the NDWI is used to measure the water content of leaves (Gao, 1996). A negative value indicates no vegetation or water content whereas a value close to +1.0 indicates the presence of water content. When used for a dam safety monitoring, it would serve a similar purpose as the NDVI.

The second variation of the definition is used to map water bodies (McFeeters, 1996). Pixels are identified as water or nonwater based on whether their NDWI values are higher or lower than a threshold, see for example McFeeters (2013). A typical usage for this variation would be to monitor approximate changes in the reservoir water level or the width of the 'beach' upstream of a tailings dam. There are many other ways to monitor reservoir water level accurately, but for tailings dams in particular the ability to monitor the beach width regularly and remotely has dam safety benefits as this property is important for controlling pore-water pressures within the tailings dam.

\subsection{Optical - iron oxide trace}

There have been numerous studies of detecting traces of iron oxides in local or large scales using multispectral optical data, see for example Ducart et al. (2016) or Van der Werff and Hewson (2020). These studies mostly involve the identification of iron oxides or clay minerals where the spectral signature of the targeted substance is relatively well defined. Based on these known spectral signatures, various standardised indices have been defined to exploit the contrasts in the surface reflectance over different spectral bands by common forms of iron oxide for example, haematite and goethite.

Studies have also shown that remote sensing optical data can be used for detection of iron oxide precipitates associated with mining drainage, see for example Anderson and Robbins (1998). When the composition of the content in a tailings dam is unknown or when its spectral signature is difficult to obtain, detection of iron oxides provides a good alternative for monitoring the tailings dam. Another common approach is to define a benchmark location where the presence of the tailings is certain and use of the corresponding surface reflectance profile as the target spectral signature.

Due to the uncertainty and variability of the spectral signature of the content of a tailings dam, it is unlikely to present a fixed set of multispectral indices and corresponding threshold-based detection methods that are suitable for all cases. Instead, simple statistical measures of similarity between multivariate data - for example, correlation coefficients, can be used to quantify the likelihood of the studied location containing substances similar to iron oxides or substances at the benchmark location. Combined with an image change detection algorithm, such as those reviewed in You et al. (2020), this statistical measure can highlight any potential abnormal increases in the presence of iron oxides or tailings over the monitored area. Figure 4 shows an example of such changes during a leakage incident.

\subsection{Radar - InSAR}

Interferometric synthetic aperture radar (InSAR) is a technique used to measure ground displacement. In contrast to optical satellites, which passively measure the solar radiation that comes off the Earth, synthetic aperture radar (SAR) satellites actively emit microwave radiation towards the Earth's surface and measure the portion of it that returns. By comparing synthetic aperture radar measurements from two different dates, InSAR produces a measurement of the change in the ground position between the two dates. By comparing observations from many dates, the movement pattern of a dam or reservoir rim over time can be obtained.

The accuracy of InSAR results is usually described as 'millimetric'. In detail, the accuracy depends on various factors including the total observation duration and the number of observation dates. Different modern satellites have roughly similar accuracies to each other. See Crosetto et al. (2008), Di Martire et al. (2014) and Sadeghi et al. (2021) for examples of validation and inter-comparison of InSAR results.

InSAR is a highly technical topic that can seem impenetrable to the uninitiated. Although the technique can be described simply as comparing pairs of images, in detail it is a complex process with many steps, as various sources of noise or errors must be corrected for. To obtain the most out of interpreting the results it is useful to have some technical expertise in the topic, so processing from input satellite data to displacement results should therefore be carried out by a specialist, who ideally should also assist from the initial feasibility assessment to the final interpretation.

The benefits of InSAR are that it can provide dense measurements over a wide area (Figures 5 and 6), which is not practical with levelling surveys, and is cost-effective in comparison to aerial, drone or terrestrial LiDAR surveys. It is not affected by cloud cover and can be done completely remotely. InSAR can either be used for a one-off study or for operational monitoring with, for example, weekly, monthly or annual updates. InSAR can also be used for retrospective analyses, such as to assess a site's history of settlement over the past five years even without any surveys having been conducted during those five years. This is possible because SAR satellites have already been routinely collecting and archiving observations over most of the world's landmasses for several years. 

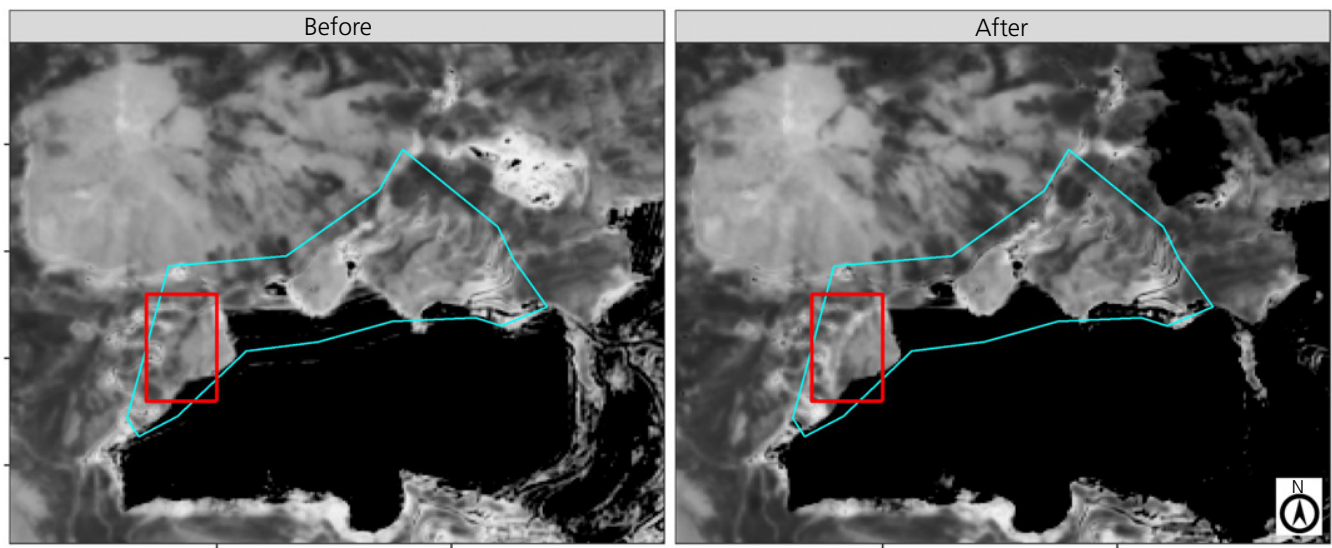

Likelihood of iron oxides

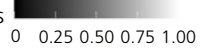

Figure 4. An example showing new traces of iron oxides detected on the downstream left mitre of a tailings dam in Peru. (Left) the iron oxide presence likelihood before the incident, and (right) the likelihood after the incident. NB: Polygon denotes area monitored, box denotes location of change detected

Table 2. Satellite datasets key considerations for dam safety monitoring

\begin{tabular}{|c|c|c|c|}
\hline Satellite dataset & Monitors & Advantages & Disadvantages \\
\hline Optical imagery & Land-use change & $\begin{array}{l}\text { Open access } \\
\text { Widely understood } \\
\text { Widely available } \\
\text { More frequently updated than land-use maps }\end{array}$ & $\begin{array}{l}\text { Resolution of open-access data may not be } \\
\text { adequate in some areas } \\
\text { Obscured by clouds }\end{array}$ \\
\hline NDVI & Vegetation health & Open access & $\begin{array}{l}\text { Natural seasonal variation needs to be } \\
\text { statistically removed from data in order to } \\
\text { spot anomalies. } \\
\text { Obscured by clouds }\end{array}$ \\
\hline NDWI & $\begin{array}{l}\text { Water surface } \\
\text { extents }\end{array}$ & Open access & $\begin{array}{l}\text { Not as accurate as traditional methods } \\
\text { Careful processing by experienced professionals } \\
\text { needed } \\
\text { Obscured by clouds }\end{array}$ \\
\hline Iron oxide trace & Pollution & Open access & $\begin{array}{l}\text { Careful processing by experienced professionals } \\
\text { needed } \\
\text { Obscured by clouds }\end{array}$ \\
\hline $\begin{array}{l}\text { InSAR (open } \\
\text { access) }\end{array}$ & $\begin{array}{l}\text { Wide area surface } \\
\text { movement }\end{array}$ & $\begin{array}{l}\text { Open access } \\
\text { Not affected by clouds } \\
\text { Historical data available in some cases }\end{array}$ & $\begin{array}{l}\text { Careful processing by experienced professionals } \\
\text { needed }\end{array}$ \\
\hline $\begin{array}{l}\text { InSAR } \\
\quad \text { (commercial) }\end{array}$ & $\begin{array}{l}\text { Wide area surface } \\
\text { movement }\end{array}$ & $\begin{array}{l}\text { Not affected by clouds } \\
\text { Better accuracy than open-access data }\end{array}$ & $\begin{array}{l}\text { Satellite may need to be re-tasked for site } \sim 1 \\
\text { year of data needed to calibrate movement } \\
\text { Can be very expensive }\end{array}$ \\
\hline GNSS & Point movement & $\begin{array}{l}\text { Continuous, real time } \\
\text { Accurate }( \pm 1 \mathrm{~mm})\end{array}$ & $\begin{array}{l}\text { Very expensive } \\
\text { Measures movement of base station only }\end{array}$ \\
\hline $\begin{array}{l}\text { Satellite } \\
\text { communications }\end{array}$ & $\begin{array}{l}\text { N/A - transfers data } \\
\text { from in situ } \\
\text { devices }\end{array}$ & $\begin{array}{l}\text { Allows real-time monitoring } \\
\text { Works in very remote areas } \\
\text { May work with existing instrumentation }\end{array}$ & $\begin{array}{l}\text { More expensive than Wifi or mobile phone } \\
\text { network solutions }\end{array}$ \\
\hline $\begin{array}{l}\text { Meteorological } \\
\text { forecast }\end{array}$ & $\begin{array}{l}\text { Predicted rainfall } 10 \\
\text { days in advance }\end{array}$ & $\begin{array}{l}\text { Both open-access (NOAA) low-resolution and } \\
\text { commercial (ECMWF) high-resolution datasets } \\
\text { are available }\end{array}$ & $\begin{array}{l}\text { To be meaningful it needs to be combined } \\
\text { with numerical rainfall-runoff models }\end{array}$ \\
\hline Soil moisture & $\begin{array}{l}\text { Leakage from buried } \\
\text { pipes or reservoir }\end{array}$ & $\begin{array}{l}\text { Allows fast regular analysis of long lengths of } \\
\text { pipeline/embankment }\end{array}$ & $\begin{array}{l}\text { Only detects moisture in top } \sim 0.05 \mathrm{~m} \text { of } \\
\text { surface } \\
\text { Poor spatial resolution }\left(\sim 1 \mathrm{~km}^{2}\right)\end{array}$ \\
\hline
\end{tabular}




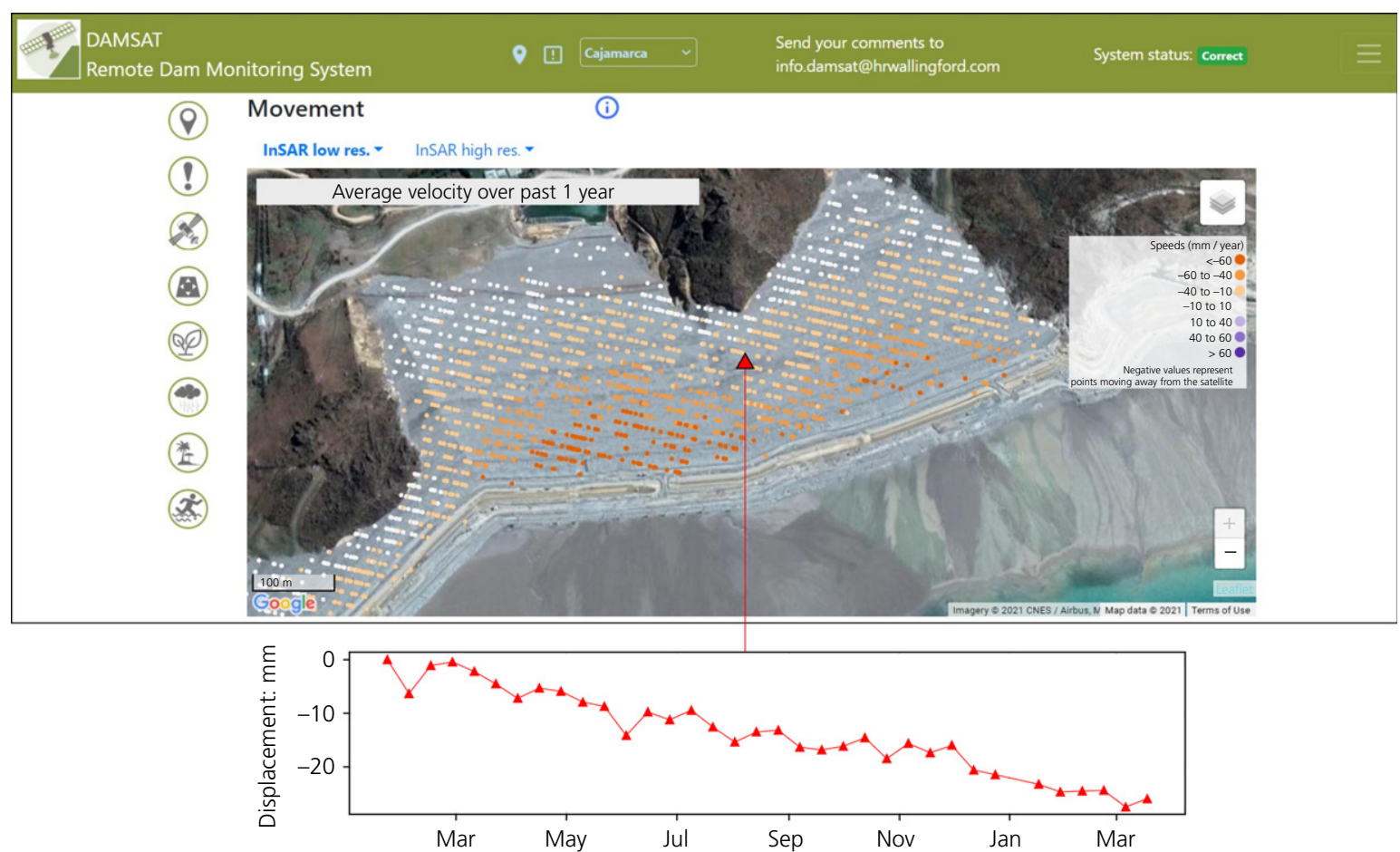

Figure 5. Graphical plot of open-access sentinel 1 InSAR data on downstream face of a dam. Note: Each dot can be interrogated to give a time-series graph of movement (Courtesy of DAMSAT). A full-colour version of this figure can be found on the ICE Virtual Library (www.icevirtuallibrary.com)

A limitation of InSAR is that it is not an inherently threedimensional (3D) technique: each InSAR dataset measures the one-dimensional (1D) component of the displacement that is in the direction that the satellite looks towards the ground (known as the line of sight), which is typically $20-45^{\circ}$ offvertical. Datasets from two different satellite viewing geometries will together give two-dimensional results and, if an assumption is made about the direction of ground displacement, such as 'all of the horizontal motion is in the damperpendicular direction', then a pseudo-3D result in terms of eastwards, northwards and vertical velocities can be obtained, usually with a small sacrifice in spatial and/or temporal resolution. How critical this limitation is to the viability of InSAR monitoring will depend on the monitoring requirements of each dam. Even 1D measurements give an idea of the rate and spatial pattern of motion and show the temporal pattern of motion - such as whether the rate is linear, seasonal or accelerating over time.

InSAR coverage depends on the ground surface, slope and aspect. Solid surfaces such as concrete or rock, and surfaces without much vegetation are favourable, so dams typically have a relatively good surface for InSAR. Vegetation, which moves independently of the ground surface, can obscure the ground movement signal. Movement data cannot be obtained over water. It should be noted that a steep dam face facing away from the satellite will not be visible from the satellite's viewing position, and a related issue can affect coverage on slopes facing steeply towards the satellite. This might mean that only one of the two or more available viewing geometries has coverage across a particular dam. To guarantee coverage, it is possible to install artificial reflectors on a dam crest, but this only improves coverage at the points where the reflectors are installed and has the associated costs of equipment and installation on site.

In common with some other surveying methods, InSAR gives relative rather than absolute measurements, so it is necessary either to choose a reference location which is assumed to be stationary, or reference the results to GNSS (see below) if available.

There is a maximum movement rate relative to neighbouring pixels that can be resolved with InSAR. For sentinel-1 in the UK where there is a 6-day revisit time, this is a differential rate of $\sim 14 \mathrm{~mm} / 6$ days between pixels $\sim 20 \mathrm{~m}$ apart. Total movement rates higher than $\sim 14 \mathrm{~mm} / 6$ days can be measured so long as the rate increases smoothly over a distance of many pixels. 


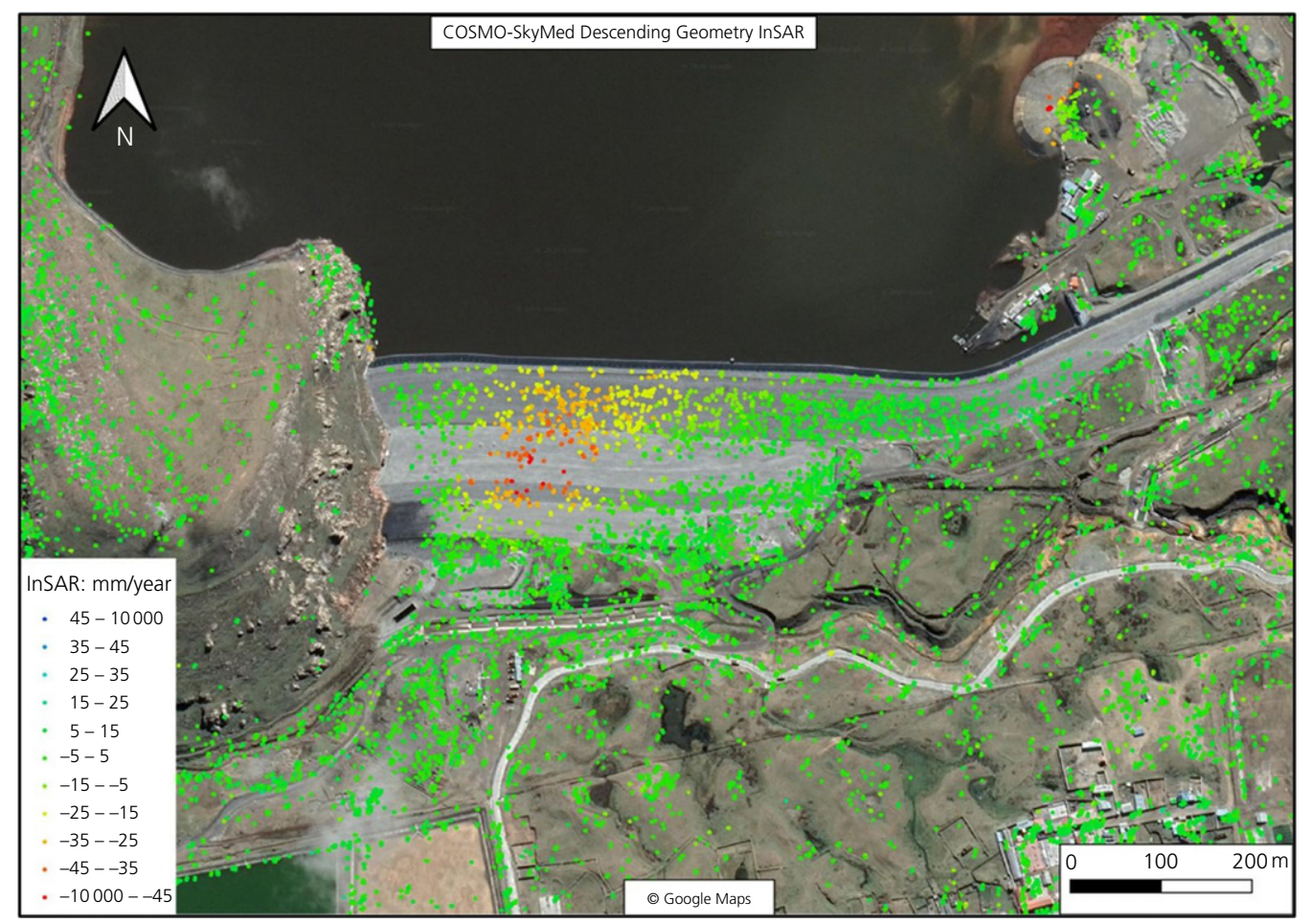

Figure 6. Graphical plot of typical commercial InSAR data on downstream face of a dam (Courtesy of E-GEOS). A full-colour version of this figure can be found on the ICE Virtual Library (www.icevirtuallibrary.com)

\subsubsection{Open access, lower resolution radar data}

The leading and most-used SAR satellites with an open data policy are the European Space Agency's twin sentinel-1A and sentinel-1B satellites. They have been collecting data since 2014 and 2016, respectively, and two more sentinel-1 satellites (1C and 1D) are in development to ensure continuity into the future (ESA, 2015).

The data are provided in single-look complex format and although they are free, there are costs to turn this into useable InSAR results. The costs arise from the computing resources required, the time of the InSAR analyst, and the time invested to develop the software. Some nations such as Norway have already made services to provide free InSAR results on an annual basis, and a continent-wide European Ground Motion Service (EGMS) is in development (Crosetto et al., 2020).

For Europe, including the UK, sentinel-1 data are collected in both ascending and descending viewing geometries every six days. The revisit time is typically 12 days for the rest of the world. Data are generally available within $24 \mathrm{~h}$ of observation, with some additional time needed for the InSAR processing. These properties, and the consistency of data collection, make sentinel-1 well suited to monitoring. The full spatial resolution is approximately $4 \mathrm{~m} \times 23 \mathrm{~m}$ (CLS, 2016) but as mentioned above in the discussion of ground surfaces, not every pixel will be useable for InSAR.

Aside from sentinel, there are archive SAR data from other satellites going back to the early 1990s, which can be used for historical studies. A limited amount of free data is available from programs such as RADARSAT and ALOS-2 but they are much less used for monitoring than sentinel-1 due to data accessibility.

\subsubsection{Commercial, higher resolution radar data}

Open-access data's spatial resolution of $\sim 4 \mathrm{~m} \times 23 \mathrm{~m}$ can be too low for monitoring smaller dams or for giving a full picture of the pattern of settlement across a dam. Commercial satellites such as the TerraSAR-X constellation and the COSMO-SkyMed constellation offer higher resolution, typically $3 \mathrm{~m} \times 3 \mathrm{~m}$. The revisit time depends on the customer needs, but can be as low as 1 day.

These satellites acquire data in places where there is consumer demand, so their archive of data is more patchy, and to arrange monitoring in a new area it is necessary to 'task' the satellite (i.e. to request that it is programmed to collect data over your area of interest). Depending on the availability of archive data, it may be necessary to wait up to a year after tasking before full ground motion results are available. 
Satellite data for dam safety monitoring

Goff, Ainscoe, Liu and Roca

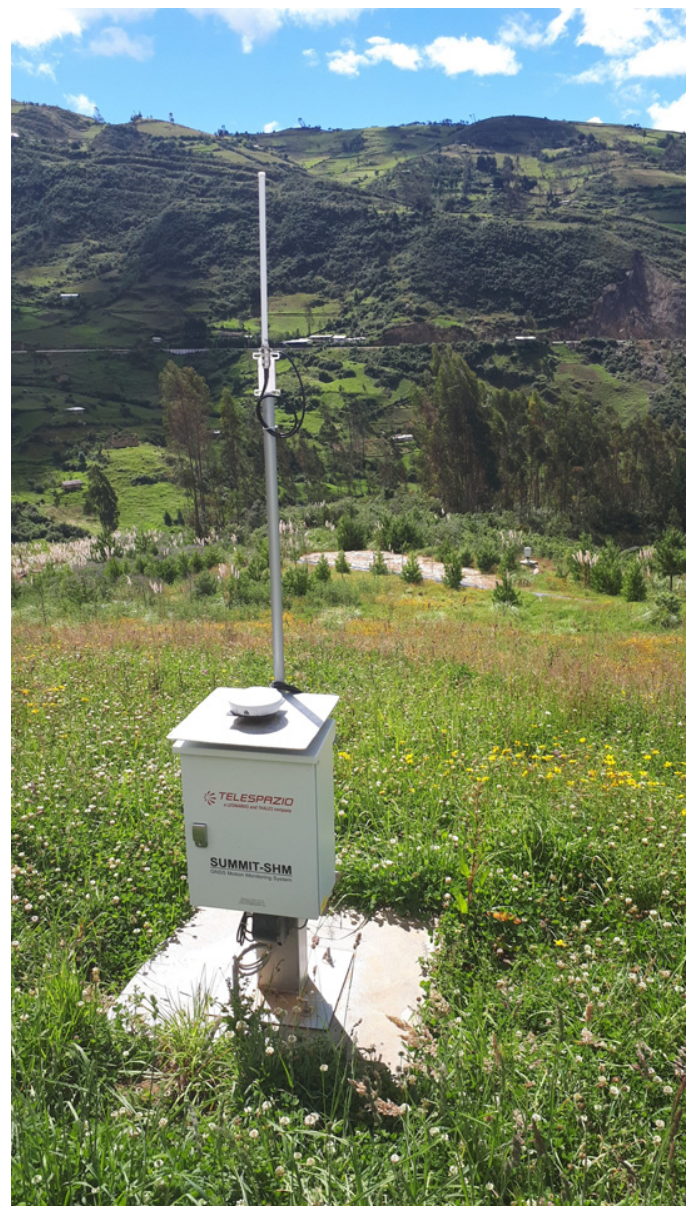

Figure 7. A SUMMIT GNSS base station installation on a closed tailings dam in Peru, monitored continuously since 2019 (Courtesy of Telespazio UK)

The commercial satellites operate using a different wavelength (band) to sentinel-1. The implications of this are usually secondary to resolution but one consequence is that the commercial satellites can have poorer coverage over heavily vegetated ground surfaces.

Pricing is per image, plus a cost for processing if required. Typical pricing is from the hundreds to low thousands of pounds per image. Overall, the commercial option is several times more expensive than using open-access data, so can be prohibitive, but using commercial data can give more choice about factors such as revisit time and, for situations requiring high resolution, can sometimes be the only InSAR option.

\subsection{Global navigation satellite systems}

Global navigation satellite systems (GNSS) is the term for systems that use a constellation of stable medium earth orbit
(MEO) satellites to enable terrestrial sensors to determine their position accurately using a precisely timed radio signal (Cifres et al., 2018). There are currently four true GNSS systems: the US global positioning system (GPS), the Russian global navigation satellite system (GLONASS), the European Galileo system and the Chinese Beidou navigation satellite system. There are also regional and national systems.

GNSS systems are now ubiquitous in cars and mobile phones for navigation purposes and the typical accuracy of these consumer devices is $2-5 \mathrm{~m}$ which is perfectly adequate for navigation. A GNSS technique known as carrier phase tracking, or real-time kinematic (RTK) tracking has been adopted by the surveying industry, and this allows closer tracking of the satellites and accuracy of $<10 \mathrm{~mm}$ (Cifres et al., 2018). The use of a static base station in addition to the monitoring points, and further processing of the data (Figure 7), can increase this to 'millimetric accuracy' (Telespazio VEGA UK, 2020).

The benefits of GNSS monitoring are that it can be very accurate, automated, allow real-time alerting and the data are not affected by cloud cover. For monitoring of an awkward to reach critical piece of infrastructure in a seismically prone area, like the valve tower in a reservoir, or a structure with a discrete known issue, such as a crack on a spillway wall, GNSS monitoring offers significant benefits.

The disadvantages are that it requires the physical installation of ground sensor infrastructure at the dam site; the ground sensors require a reliable power source and internet connection to transmit the data; it is very expensive ( $\left.\_60 \mathrm{k} / \mathrm{year}\right)$ when compared to a periodic manual survey ( $£ 1 \mathrm{k} / \mathrm{year})$; and it only measures movement of the point of the sensor. This means if a problem develops a few metres away from the sensor it may not be detected.

\subsection{Satellite communications (SatComms) for in situ sensors}

Many types of digital instrumentation equipment exist for monitoring various aspects of dam safety. These include vibrating wire piezometers, flow meters, radar water-level sensors, crack and tilt gauges, seismometers and many others. The benefits of collection, combination and presentation of such data have been demonstrated before (Goff et al., 2016) and commercial systems such as Tableau by Salesforce, and RTIM by HR Wallingford (ICE, 2016) are now available to facilitate this. However, one of the biggest barriers to such a monitoring system can be transmitting the data from the site location. Often, the very sites that would benefit most from remote monitoring are so remote that there is no electricity supply, no wi-fi connection and no mobile phone network coverage. 
In such cases, the use of a satellite data connection can be an effective solution. Working in a similar way to a mobile phone network data connection, data are sent to satellites and from there connected to the internet, where it is retrievable.

The benefits of using SatComms are that existing monitoring infrastructure can be incorporated into a remote monitoring system, the data connection is reliable and can be directly compared to historical records. While the disadvantage of using a SatComm connection is that can be up to ten times the (low, data-SIM only) cost of using a $3 \mathrm{G} / 4 \mathrm{G}$ mobile phone data connection, it is still likely to be much cheaper than providing a wired/wi-fi internet connection.

\subsection{Meteorological forecast data}

Weather forecasts derived from satellite data and models can provide useful information to dam operators if combined with appropriate hydrological and reservoir models.

Weather forecasts are obtained from computer models which take the current weather observations from satellites and other sources as input. Satellites monitor the development of weather and environmental events including tropical systems, tornadoes, flash floods, dust storms, volcanic eruptions, and forest fires.

The global forecast system (GFS) worldwide model from the National Oceanic and Atmospheric Administration (NOAAUS) provides six-hourly rainfall predictions up to 10 days in advance, and is available for download from the NOAA web portal. The GFS is a coupled model, composed of four separate models (an atmosphere model, an ocean model, a land/soil model and a sea ice model). Another source of worldwide rainfall forecasts is the European Centre for Medium-Range Weather Forecast (ECMWF), which provides twice-daily rainfall predictions up to 5 days in advance.

Hydrological models estimate the runoff generated at the reservoir catchment produced by the predicted rainfall. In flood forecasting it is common to use models based on a probability distributed modelling (PDM) because they allow tracking of the soil moisture conditions at the start of each forecast period.

Once the runoff is estimated, reservoir storage models can simulate the increase of water level in the reservoir and any corresponding spillway or dam crest overflow rates. This helps dam operators to plan and manage the dam operation according to weather forecasts.

\subsection{Soil moisture}

Soil moisture can be measured by satellite to a certain extent. Satellites measure microwaves emitted by or reflected from the Earth's surface, and the intensity of the measured signal is proportional to the amount of water in the soil (Kim et al., 2019).
Data are available from open-access sources such as the European Space Agency's (ESA) twin sentinel-1 satellites and the soil moisture active passive (SMAP) satellite of the US National Aeronautics and Space Administration (NASA). However, as this technique has, until recently, only been capable of detecting moisture in the uppermost $(\sim 50 \mathrm{~mm})$ of the soil surface, and as the datasets have a coarse spatial resolution ( $1 \mathrm{~km}^{2}$ for ESA's sentinel-1, and $\sim 40 \mathrm{~km}^{2}$ for NASA's SMAP) it is of limited use to the dam safety profession in isolation.

Opportunities to combine soil moisture data with other satellite datasets offers more potential. A recent paper (Kumar et al., 2021, p. 357) states that 'Sentinel-1 synthetic aperture radar (SAR, active microwave sensor) data has opened up a new research area to develop high-spatial-resolution soil moisture products for agricultural applications. Several studies have shown the potentials of Sentinel-1 SAR data and highresolution optical data along with operational products (like SMAP) to downscale the coarse soil moisture data to retrieve high spatial soil moisture at a regular interval over vegetationcovered surfaces. However, future sensors are required to estimate soil moisture from depth up to $0.7-1 \mathrm{~m}$ (microwave sensors with $\mathrm{P}$ band) over sparse vegetation areas and varying surface roughness using active and passive microwave sensors.'

Clearly this field is still evolving, and Kim et al. (2019) offer an excellent commentary on both the history and outlook of satellite-derived soil moisture monitoring.

Currently, due to the coarse spatial resolution, it is suggested that for a reservoir retained by a large grassed earth embankment dam, the large surface area of grass may make this a suitable site for consideration of satellite soil moisture monitoring data. In most other cases however, better information on the wetness of the ground in the vicinity of a dam can be inferred from NDVI satellite data.

\subsection{Summary of satellite monitoring dataset - key considerations}

With many of the datasets described above, obtaining the data from the satellite is only the first step. Significant amounts of time and experience are required to download, check and verify the large volumes of data, process it to give meaningful results and then run statistical analyses on the results to identify change. Determining whether that change is anomalous and if so, a potential concern, is the final step. The advent of artificial intelligence (AI) algorithms has allowed this process to be partly automated and there are several commercial suppliers now claiming to offer such services. For best results, AI algorithms depend on large datasets of historical information and 'training' on what is normal and what is an anomaly by subject matter experts (i.e. dam safety engineers). 


\section{Conclusions}

It is the opinion of the authors that satellite data have great potential to improve the monitoring of dams in a variety of specific and limited ways as described in this paper, and hence to improve dam safety. Careful processing by experts and understanding of the limitations of the data is necessary. In the near future, satellite monitoring of dams by owners will tend to supplement traditional methods, and is likely to include higher cost, high precision datasets. In contrast, regulators can now use lower cost open-access satellite monitoring to keep track of indicators of issues on large numbers of dam assets that they have oversight of, providing a wealth of information previously unavailable to them.

Table 2 summarises the key considerations of each satellite dataset for dam safety monitoring, and is intended as a guide to assist dam operators and regulators in selecting the most appropriate type of satellite data for their particular needs.

\section{Acknowledgements}

The authors acknowledge the UK Space Agency (UKSA) and the Global Challenges Research Fund (GCRF) for funding the DAMSAT Project (http://www.damsat.org). The DAMSAT Team was led by HR Wallingford and included Telespazio UK, Siemens Corporate Technology, Satellite Applications Catapult, Oxford Policy Management, Smith School of Enterprise at Oxford University, Ciemam SAC, the National Foundation for Hydraulic Engineering (Peru), and the University of Cajamarca (Peru). Colour versions of all figures in this paper are available from the corresponding author on request.

\section{REFERENCES}

Anderson J and Robbins E (1998) Spectral reflectance and detection of iron-oxide precipitates associated with acidic mine drainage. Photogrammetric Engineering and Remote Sensing 64: 1201-1208.

BRE (1999) An Engineering Guide to the Safety of Embankment Dams in the United Kingdom. Building Research Establishment, Construction Research Communications, Watford, UK

Cifres R, Cooksley G and Dixon C (2018) Space technologies for dam monitoring. In Smart Dams \& Reservoirs, Proceedings of the 20th Biennial Conference of the British Dam Society (Andrew P (ed.)). ICE Publishing, London, UK, pp. 411-421.

CLS (Collecte Localisation Satellites) (2016) Sentinel-1 Product Definition, Issue 2.7, reference S1-RS-MDA-52-7440. See https:/dragon3.esa.int/web/sentinel/user-guides/sentinel-1-sar/ document-library/-/asset_publisher/1dO7RF5fJMbd/content/ sentinel-1-product-definition (accessed 04/03/2021).

Crosetto M, Monserrat O, Bremmer C et al. (2008) Ground motion monitoring using SAR interferometry: quality assessment. European Geologist 26: 12-15.

Crosetto M, Solari L, Mr'oz M et al. (2020) The evolution of wide-area DInSAR: from regional and National Services to the European ground motion service. Remote Sensing 12: 2043, https://doi. org/10.3390/rs12122043.

Di Martire D, Iglesias R, Monells D et al. (2014) Comparison between differential SAR interferometry and ground measurements data in the displacement monitoring of the earth-dam of Conza della Campania (Italy). Remote Sensing of Environment 148: 58-69, https://doi.org/10.1016/j.rse.2014.03.014.
Ducart D, Silva A, Toledo C and Assis L (2016) Mapping iron oxides with Landsat-8/OLI and EO-1/Hyperion imagery from the Serra Norte iron deposits in the Caracas Mineral Province, Brazil. Brazilian Journal of Geology 46(3): 331-349, https://doi.org/10.1590/23174889201620160023.

ESA (European Space Agency) (2015) See http://www.esa.int/ Applications/Observing_the_Earth/Copernicus/Sentinel-1/Deal_ sealed_for_new_Sentinel-1_satellites (accessed 18/02/2021).

Gao B (1996) NDWI - a normalized difference water index for remote sensing of vegetation liquid water from space. Remote Sensing of Environment 58(3): 257-266, https://doi.org/10.1016/S0034-4257 (96)00067-3.

Goff CA, Gimeno O, Atyeo MS and Wetton MN (2016) Dealing with data: innovation in monitoring and operation and maintenance of dams. Dams and Reservoirs Journal 26(1): 5-12.

Goff C, Atyeo M, Petkovsek G, Roca M and Kitamura Y (2020) The origins of large dam engineering and factors contributing to dam longevity. Dams \& Reservoirs Journal 30(3): 97-104.

ICE (2016) Institution of Civil Engineers, Real-Time Monitoring of a Remote Welsh dam, 15/02/16. Event Archive, UK, See https://www. ice.org.uk/eventarchive/real-time-monitoring-of-a-remote-dam (accessed 28/12/2020).

ICOLD (2017) Internal Erosion of Existing Dams, Levees and Dikes and Their Foundations Bulletin 164. International Commission on Large Dams, Paris, France.

Kim S, Zhang R, Pham H and Sharma A (2019) A review of satellitederived soil moisture and its usage for flood estimation. Remote Sensing in Earth Systems Science 2: 225-246, https://doi.org/ 10.1007/s41976-019-00025-7.

Kumar AK, Setia R, Pandey DK et al. (2021) Soil moisture retrieval techniques using satellite remote sensing. In Geospatial Technologies for Crops and Soils (Mitran T, Meena RS and Chakraborty A (eds)). Springer, Singapore, Singapore City, pp. 357-386. https:// doi.org/i:443.webvpn.fjmu.edu.cn/10.1007/978-981-15-6864-0_10.

Lillesand T, Kiefer RW and Chipman J (2015) Remote Sensing and Image Interpretation, 7th edn. Wiley, New Jersey, NJ, USA.

McFeeters SK (1996) The use of the Normalized Difference Water Index (NDWI) in the delineation of open water features. International Journal of Remote Sensing 17(7): 1425-1432, see https://www.tandfonline.com/doi/abs/10.1080/01431169608948714 (accessed 04/03/2021).

McFeeters SK (2013) Using the Normalized Difference Water Index (NDWI) within a geographic information system to detect swimming pools for mosquito abatement: a practical approach. Remote Sensing Journal Online 5(7): 3544-3561, https://doi.org/ $10.3390 / \mathrm{rs} 5073544$.

Sadeghi Z, Wright TJ, Hooper AJ et al. (2021) Benchmarking and intercomparison of sentinel-1 InSAR velocities and time series. Remote Sensing of Environment 256: 112306, https://doi.org/10.1016/j.rse. 2021.112306.

Telespazio VEGA UK (2020) SUMMIT-SHM State-of-the-art GNSS Motion Monitoring System Brochure. 'SUMMIT-SHM Brochure R1r0.pdf'. Telespazio UK Ltd, Capability Green, Luton, Bedfordshire, UK. See https://telespazio.co. uk/en/innovation/summit-shm (accessed 28/12/2020).

Van der Werff H and Hewson R (2020) Using Sentinel-2 MSI for mapping iron oxide minerals on a continental and global scale. Proceedings of the AGU 2019 Fall Meeting, San Francisco, CA, USA, https://doi.org/10.1002/essoar.10501783.1.

You Y, Cao J and Zhou W (2020) A survey of change detection methods based on remote sensing images for multi-source and multiobjective scenarios. Remote Sensing Journal Online 12: 2460, https://doi.org/10.3390/rs12152460. 